\title{
As microterritorialidades nas cidades: reflexões sobre as convivências homoafetivas e/ou homoeróticas
}

\section{The micro territorialities in the cities: reflections about the homoaffective and/or homoerotic conviviality}

\author{
Benhur Pinós da Costa \\ benpinos@gmail.com \\ Universidade Federal de Santa Maria
}

\begin{abstract}
Resumo: A urbanidade atual é caracterizada pela convergência de diversidades culturais que se apropriam de espaços em proximidade. Os jogos de identificações são complexos e perpassam os questionamentos subjetivos dos sujeitos e as objetividades produzidas por grupos de interação. Ocorre uma interferência do mercado produzindo espaços de consumo que fortalecem certas identificações de determinados agregados sociais. Grupos que muitas vezes são considerados homogêneos, como os de sujeitos orientados sexualmente para o mesmo sexo, diversificam suas expressões e propósitos de interação. A relação multicultural que gera tolerância e também discriminação se processa de forma complexa e se diferencia quanto ao tamanho da cidade e à diversificação do mercado cultural. A discussão sobre microterritorialidades urbanas é fundamental nas pesquisas sobre esta temática.
\end{abstract}

Palavras-chave: Microterritorialidades. Espaços de proximidade. Multiculturalismo. Espaço urbano. Homoafetividades. Homoerotismo.

\begin{abstract}
The current urbanity is characterized by convergence of different cultures which appropriate spaces in proximity. The games identifications are complex and run though the subjective questions of one and the objectivities produced by interacting groups. There is a market interference that produces consumer spaces that strengthen certain identifications of certain social aggregates. Groups that are often considered to be homogeneous, such as the ones who were sexually oriented to the same sex, diversify in their forms and purposes interactions. The multicultural relationship that generates tolerance and also prejudice takes place in complex and differs in size and diversification of the city's cultural market. The discussion on urban micro territorialities is fundamental research on this subject.
\end{abstract}

Keywords: Micro territoriality. Proximity spaces. Multiculturalism. Urban space. Homoaffection. Homoeroticism.

Resumen: El urbanismo actual se caracteriza por la convergencia de las diversidades culturales que se apropian de los espacios en proximidad. Los juegos de identificaciones son complejos y subyacen a los cuestionamientos subjetivos de los sujetos y las objetividades producidas por grupos de interacción. Ocurre una interferencia del mercado produciendo espacios de consumo que refuerzan ciertas identificaciones de determinados agregados sociales. Los grupos que a menudo son considerados homogéneos, como los sujetos orientados sexualmente para el mismo sexo, diversifican sus expresiones y propósitos de la interacción. La relación multicultural que genera la tolerancia y también la discriminación se procesa de forma compleja y difiere en el 
tamaño de la ciudad y la diversificación del mercado cultural. La discusión de micro territorialidades urbanas es fundamental en las pesquisas de este tema.

Palabras clave: Micro territorialidades. Espacios de proximidad. Multiculturalismo. Espacios urbanos. Homoafectividades. Homoerotismo.

\section{INTRODUÇÃO}

Partimos da construção da ideia de objetivação dialética da sociedade (COSTA; HEIDRICH, 2007): uma estrutura organizada e normativa que regra os sujeitos e/ou uma condição fluida e mutante condicionada a uma diversidade de eventos e à criatividade produtiva dos grupos humanos.

Primeiramente ocorre a ideia de uma sociedade que é organizada e normatizada pela objetividade dos procedimentos a serem cumpridos, inseridos em instituições sociais. Por outro lado, fazendo parte das teorias desconstrutivistas da segunda metade do século $X X$, ocorre, como objeto de renovação necessária às ciências sociais, a ação espontânea dos sujeitos em interação. Esta última ideia aponta para o desenvolvimento dos estudos dos fenômenos e situações sociais singulares em formas "multiespectrais", cujas singularidades se observam em diferentes escalas e condições espaço-temporais múltiplas. É nesta perspectiva que se concentram as análises deste texto.

Observamos as territorializações das relações homoafetivas nas cidades brasileiras a partir do imperativo situacional do espaço social, em que situações de espaço e tempo singulares produzem diferentes intensidades de ação da rigidez estrutural e normativa da sociedade, assim como também possibilitam fazer fluir autenticidades dos diferentes sujeitos sociais. A isto se explica a microterritorialidade, no caso deste texto, a territorialização das convivências homoafetivas e/ou homoeróticas em pequenas partes (apropriadas) do espaço social: por um lado, essa (micro) territorialidade implica a representação das normativas e padrões sociais vigentes, por isso da existência territorial como controle dos desviantes; por outro lado, representa o espaço delimitado de autenticidade, como um refúgio ou uma ilha de autenticidade relacional por entre as perspectivas objetivas do mundo social.

\section{A DIALÉTICA MICROTERRITORIAL URBANA}

Em relação à desconstrução da ideia de uma estrutura rígida da sociedade e das reproduções de normas, funções e definições morais nos corpos e subjetividades dos indivíduos, apresentamos algumas ideias. Primeiramente, tem-se a da emergência dos sujeitos e grupos culturais "em desacordo" (VELHO, 1989) com o cumprimento dos scripts sociais (SEMPRINI, 1999), que se referem à regulamentação de suas vidas, emoções e ações. 
Em segundo lugar, aparece a ideia da reestruturação da ação capitalista. Isso se refere às estratégias do mercado flexível que incentiva a expressão social da diversidade cultural (em diferentes escalas) para, assim, promover o consumo (JAMESON, 1991). Para alguns (JAMESON, 1991; MACLAREN, 2000), as definições de uma sociedade multicultural não podem ser desatreladas de condições estruturantes, isso porque são compostas por centros de poderes hegemônicos, tanto político-culturais (como a prevalência da neutralidade inquestionável e da "branquidade", por exemplo), como político-econômicos (como prevalência do modo de produção capitalista e a sua inexorável habilidade de diversificar os grupos humanos para promoção do consumo e a especialização do labor, mas unificar estes grupos pela condição monopolística da técnica, da ciência, da acumulação e do controle).

Por outro lado, há ainda a ideia de que, além de uma condição estruturante hegemônica que converte a sociedade em diversidades de nichos consumistas fabricados e artificiais, a marginalização de uma série de segmentos sociais e situações culturais (locais e regionais) convertem-se em lugares de promoção da originalidade e da arte da sobrevivência. Muitos desses compostos multiculturais, produzidos em situações marginais e de risco (social e ambiental) e/ou em situações de hesitação das ações capitalistas à própria anexação deles às relações de produção e de consumo (como em regiões ainda não modernizadas e deixadas em contextos de reserva de mão de obra e/ou riquezas naturais), acabam convertendo-se como situações contra hegemônicas (SANTOS, 2002) ou de negação a imposição de práticas culturais e econômicas capitalistas ocidentais.

É em relação a este tripé dialético que os sujeitos sociais compõem suas subjetividades e tornam reais e diversificadas suas vivências urbanas: (a) por um lado, eles apresentam uma espontaneidade de ação composta na formação de sua subjetividade, que coloca em xeque valores construídos socialmente, seja ela discordante ou concordante aos valores normalmente estabelecidos; (b) por outro lado, tais sujeitos ainda cumprem scripts e/ou normativas sociais, pois são regidos por um conjunto de diretrizes compostos em instituições sociais; (c) e, ainda, suas subjetividades são mobilizadas por estratégias publicitárias de mercado que se confundem com seus próprios desejos e/ou próprias regras de convivência em certos grupos sociais.

Sujeitos sociais, então, apresentam-se como atuantes sociais, pois: não somente representam papéis e funcionam conforme uma cena social (GOFFMAN, 1996); não somente estão condicionados a uma materialidade e a um conjunto de procedimentos, assim como não se significam somente em relação a um conjunto de significantes sociais (FOUCAULT, 1993); não somente exercem sua arte de fazer e/ou são criativos conforme situações apreendidas contidas em um cotidiano prático (DE CERTEAU, 1994); não somente agem conforme um grupo imediato cujos princípios e valores produzem uma cultura que se confunde com a expressão de seus atos (DUNCAN, 2003); e não somente apresentam-se alienados a uma estrutura complexa que os particulariza de acordo com a particularidade de seu contexto operacional no conjunto de engrenagens que representam a sociedade (HELLER, 1991). 
Os sujeitos sociais são esse conjunto de "não somentes", pois a tudo isso eles se referem, mas não exatamente a cada um destes atributos. Como categoria que universaliza a todos que pertencem a uma sociedade, os sujeitos, ao mesmo tempo em que a reproduzem também a modificam. Suas expressões apontam para uma concordância para com os procedimentos e condições objetivas das instituições sociais, como também apontam para um grupo imediato a que pertencem e para a originalidade de sua criatividade, como um conjunto de posições construídas subjetivamente e objetivadas em suas ações cotidianas.

A própria originalidade dos sujeitos pode estar composta por um par dialético que representa, por um lado, a complexidade das situações apreendidas socialmente e, por outro, o ser agindo espontaneamente produzindo situações novas para com o contexto social e para com o próprio "si mesmo". A imprevisibilidade de suas ações compõe a imprevisibilidade das situações sociais, mesmo que composto a um conjunto de determinantes que podem ser apreendidos em grande escala, quando pensamos na composição de um grupo social imediato, como em pequena escala, quando pensamos a composição das normativas de um conjunto de instituições universalizantes que produzem o que se pensa como sociedade.

As próprias ações dos sujeitos podem não ser representativas de uma identificação estanque para consigo mesmo. Os sujeitos agem para se encontrarem, ou seja, "em busca de si mesmos" (TOURAINE; KHOSROKKHAVAR, 2004). A cada situação apreendem significantes sociais (estruturantes de uma cultura localizada ou ao que se referem à universalidade da sociedade) e/ou se convertem no "outro significante", como espelho para "o si mesmo". Mas as situações sociais se diferenciam, assim como se diferenciam os significantes da situação para consigo mesmo. A cada situação, os sujeitos sociais se significam e a significam. Nessa interação, apresentam identificações em relação "a si mesmo", em relação aos "outros" e em relação àqueles todos mais distantes ao conjunto que define o "nós".

A composição dos significados e identificações é complexa e apresentam-se nos sujeitos como um "eu" que representa uma segunda pessoa que fala com o "mim" (MEAD apud HOLLAND, 1979; MEAD apud HONNETH, 2003). A cada interação e situação social, os sujeitos objetivam a si mesmos como uma expressão de "mim" que é subjetivamente produzida pelo diálogo com o "eu" (aquela "pessoa" que fala e que nos dá possibilidades de significação, identificação e formas de ação). Neste sentido, as interações entre sujeitos convergem uma complexidades de posições significantes: (a) os significantes apreendidos subjetivamente pelo "eu" (que representa a ação criativa do sujeito em "mim" de acordo, em aprendizado incompleto, ou em desacordo com a situação social); (b) os significantes apreendidos coletivamente no grupo cultural imediato (que determina as representações coerentes a todos os sujeitos que convivem em situação, já compostas no "eu" subjetivo de cada um e que mobiliza a representação de "si" e dos "outros", sejam estes "outros" ou insiders, ou marginais/periféricos, ou outsiders da interação); (c) os significantes que os sujeitos (normalmente composto em relação ao "nós" e/ou fazendo parte das representações do grupo) organizam em relação a suas representações para 
com a universalidade da sociedade (muitas vezes mobilizam recursos simbólicos construídos socialmente identificando-se com determinados símbolos e valores e/ou reinventando as condições deles).

Estas relações se compõem em situação de interação social. É na interação que sujeitos operam significantes sobre o "si", sobre o "nós" imediato, sobre os "outros" marginais e outsiders e sobre suas relações, representações e significados para com um conjunto de determinantes da universalidade da sociedade.

As interações apresentam-se como uma composição híbrida e complexa de significados que certos sujeitos compartilham e somente compartilham na interação. Na interação, os sujeitos se posicionam conforme a composição estabelecida. Esta composição também depende da situação espaço-temporal em que ocorre, ou seja, converge a um contexto material (uma parte do espaço e/ou lugar) e um contexto temporal, ou seja, certos elementos representativos da situação apresentam-se pelo compartilhamento de um tempo de ocorrência que constantemente se transforma, sendo a lentidão da transformação dependente da necessidade de os sujeitos manterem a identificação sobre o "si mesmo" e sobre os outros diretos com que convive, em tempos assíncronos, que definem a continuidade representativa de um conjunto de situações de interação.

Por outro lado, as representações sociais universalizam certos contextos de interação determinando a identificação deles. Os sujeitos em interação acabam mobilizando estes mesmos recursos de identificação para transformá-los e representarem a "si mesmos". Muitas vezes, as representações sociais estão longe de determinarem a significação do que ocorre em uma situação, mas, ao mesmo tempo, compõe os significados sobre o que ocorre numa contínua operação individual e coletiva de modificar (supervalorizando ou depreciando certos elementos expressivos) tais significantes.

Categorizamos as situações de interação social, levando as discussões sobre as quais discorremos aqui, como "microterritorializações", pois elas se definem pela relação espaço-temporal de ocorrência. Elas se compõem pela operacionalidade objetiva das ações dos sujeitos sociais, que constroem ou se apropriam de uma materialidade, compondo a estética dos corpos, das performances individuais e o compartilhamento coletivo das indumentárias e as marcações dos cenários que possibilitam as expressões (os lugares de ocorrência).

Elas se compõem também do tempo que converge para a situação em si (no tempo que possibilita a mobilização de determinadas representações sociais, pois elas compõem o que existe e o que se valoriza em um dado período) e no tempo assíncrono que representa individual e coletivamente a situação que se prolonga em um determinado espaço, ou seja, compõe um conjunto de presenças, performances e trocas de significados e identificações que se define por um período de existência (aqui a microterritorialização perdura por uma qualidade que se reproduz ao longo de um tempo).

As microterritorializações identificam lugares e quem está nos lugares, compondo as representações individuais e coletivas dos sujeitos. Essa identificação se estabelece socialmente, seja cotidianamente, contida nas representações de uma comunidade localizada, seja na universalidade de certos discursos contidos em instituições sociais, como a 
ciência, como o Estado, como os discursos da mídia e da publicidade. Cabe às pesquisas em ciências sociais complexificarem as identificações de certas situações de interações sociais conforme as discussões que estabelecemos aqui.

\section{OS SUJEITOS, AS IDENTIDADES, AS POLÍTICAS E AS MICROTERRITORIALIDADES HOMOAFETIVAS}

Os sujeitos sociais inicialmente confundem-se com as representações sociais que se estabelecem sobre eles. Observamos que ocorre, na segunda metade do século XX, a intensificação da diversificação social a partir da produção de identidades que definem os sujeitos. Em primeiro momento, essas identidades ocorrem pela necessidade política de transformação dos estigmas em vistas à inserção social por igual, determinando os mesmos direitos a todos e buscando medidas de combate à discriminação e o preconceito em qualquer nível de relações cotidianas. Por um lado, vão ocorrer movimentos sociais que se referem mais à diferença de inserção econômica de determinados segmentos na sociedade, por outro lado, vão ocorrer movimentos que se atrelam mais às questões culturais sobre a ocorrência de estigmas sociais (SEMPRINI, 1999).

O principal elemento político que vai definir os movimentos sociais, desde os anos 60 , é a identidade. A identidade une e representa um conjunto de sujeitos que se apresentam como uma parcela importante de certa população, mesmo que determinada como minoria, como estigmatizada e/ou marginalizada. As identidades vão se produzir novamente como encaixes sociais (GIDDENS, 2002), porém, o que politicamente vai mudar neste momento é a emergência dos discriminados que se mobilizam para combaterem os preconceitos sociais que sofrem.

As identidades mudam seus determinantes políticos: anteriormente os poderosos que determinavam as identidades estigmatizadas dos sujeitos discriminados, posteriormente, os discriminados se apegam às suas identidades para lutarem por justiça social, combate ao preconceito e inserção econômica. No entanto, muitos dos atributos mobilizados pelos próprios sujeitos discriminados são operacionalizados socialmente como discursos e práticas políticas de valoração social sem efetivamente fazer uma crítica e revelarem o cruel componente político hegemônico contido nestas próprias expressões (MACLAREN, 2000). Eles reproduzem os próprios atributos que determinam o preconceito que sofreram e sofrem. As políticas quanto à diversidade cultural, a partir da configuração de um tipo ideal de cultura, raça ou situação econômica, ainda se definem pela existência de um polo hegemônico em que não se questiona e não se configura como um agente de poder, ou seja, refugia-se na neutralidade. O exemplo disso, discutido por Maclaren, é a despreocupação com o polo neutro que configura uma "branquidade" hegemônica e pelo qual os atributos de culturas étnicas são exauridos para configurarem um conjunto de sujeitos pertencentes a tais culturas.

Louro (2001) e Silva (2009) discutem uma virada cultural que ocorre nas últimas décadas do século XX e que se configuram por um conjunto de teorias e teóricos que se 
denominam Queers. Essas questões emergem devido à difícil realização dos discursos que observavam a construção de identidades estaques que compunham um conjunto de estigmatizados e/ou marginalizados sociais. O movimento feminista, por exemplo, foi atacado por movimentos de mulheres negras e de segmentos sociais marginalizados que alegaram que os atributos que produziam uma identidade política de mulher estavam condicionados a um modelo de mulher branca e de classe média, divergente das condições cotidianas em que viviam. Outro exemplo se configura pela qualidade homogeneizante do movimento gay determinado pelos lemas de "sair do armário" e "assumir-se". Autores como Parker (2002) e Braga Junior (2006) observam que as expressões dos sujeitos e as configurações de culturas homoeróticas locais são muito diversas e não podem estar condicionadas a determinações de uma identidade ou de um conjunto de atributos que se denominam de gays. Se existe uma identidade que se refere a gay, isso aponta mais como um "pastiche" que como uma configuração estanque de atributos. Neste sentido, o que se observa é a existência de uma "interseccionalidade" da identidade que define um conjunto de "posicionalidades" que os sujeitos assumem em situações diferenciadas em seu cotidiano. Isso compõe "espaços paradoxais" quanto à assunção de suas expressões e determinação de seus comportamentos (SILVA, 2009).

Como discutimos anteriormente, os sujeitos mobilizam subjetivamente identificações sobre "si mesmos", compostas socialmente, e objetivam certas expressões e comportamentos de acordo com a relação que estabelecem com outros em um espaço de interação. Sua identidade é interseccionada e certos atributos dela condizem mais com suas performances em determinados espaços de interação do que com outros. Assim suas vidas se diversificam em condições espaço-temporais diversas de identificação, expressão e comportamento. Neste sentido, as microterritorializações são estas condições espaçotemporais que evidenciam a interação social que produzem e são produzidas pelas relações dos diferentes sujeitos que objetivam de diferentes formas atributos contidos em suas subjetividades, em constantes diálogos sobre "si mesmos", que são ocasionados pelos seus contados e espelhamentos para com "os outros".

A emergência de uma identidade cultural que se define primeiramente como um estigma e, posteriormente, como um modelo de identidade e/ou cultura alternativa de uma minoria que solicita justiça social, assim como pleno exercício de suas especificidades produz um constante jogo de visibilidade e invisibilidade por entre o espaço urbano, como é o caso do cotidiano de sujeitos orientados sexualmente para o mesmo sexo. Os comportamentos quanto a uma sexualidade homoerótica foram banidos da sociedade e se definiram como atributos que estigmatizam os sujeitos. Por outro lado, os encontros homoeróticos e as homoafetividades sempre ocorreram de forma "camuflada" como "táticas espertas" de sujeitos por entre "brechas" do espaço urbano. Tais táticas apresentaram-se como fundamentalmente espaciais, marcando lugares e trajetos da cidade nos quais sujeitos transitavam/transitam em busca de experiências eróticas e afetivas. Tais lugares e trajetos espaciais se produzem como "rizomas" (DELEUZE, 1996) e/ ou microterritorializações (COSTA, 2002; COSTA 2008), cujas pequenas parcelas do espaço ("cantos" e "pedaços" de praças e ruas, trajetos de deslocamento, assim 
como certas frequências em determinados estabelecimentos como bares e, até mesmo, instalações públicas) são tenuamente apropriados por um agregado de sujeitos que se fazem presentes e exercem certas práticas.

A emergência de um mercado de diversão, principalmente noturna, ligada à música e ao show business, é conduzida pela diversidade das práticas afetivas e sexuais daqueles frequentadores e consumidores dos lugares de diversão. $O$ primeiro ato de manifestações gay, considerado um dos marcos da emergência do movimento, foi a defesa quanto à liberdade de práticas de sujeitos gays em seu lugar de encontro: a reação à batida policial em Stonnewall Inn, bar frequentado por homossexuais em Nova York, em 1969. Nos anos 70 e 80, abrem-se por todo mundo bares e boates destinados aos encontros, liberdades e práticas sexuais e afetivas homoeróticas. A famosa boate Studio 54 torna realidade o gosto gay pela produção da indústria musical embalada pela disco music dos anos 70 e pela dance music dos anos 80 . O corpo torna-se performático e imita os gestos e os trejeitos em movimentos alegres e exagerados das divas da dance music. A alegria e o colorido que se cultua (mesmo que de forma encerrada) nos lugares de diversão noturna gay libertam-se ao espaço público para a apoteose das paradas gays. Gay torna-se significado de libertação quanto a uma definição masculina rude e a possibilidade performática do corpo de tornar-se feminino, de se demonstrar alegre e exagerado quanto aos comportamentos e quanto às suas representações na realidade. Gay apresenta-se como um culto ao movimento, à dança frenética, a adoração às divas da musica pop e a reprodução da vida como uma passarela de moda ou como um vídeo clipe (principalmente devido ao aparecimento da MTV nos anos 90). Todos orientados sexualmente para o mesmo sexo deveriam experimentar o padrão alternativo gay, assumir-se e "sair do armário".

Por outro lado, em relação a este modelo gay atrelado às práticas e expressões das festas gay, vinculado essencialmente ao mercado de classe média, uma diversidade de sujeitos orientados para o mesmo sexo acabam não se inserindo ou inserindo-se provisoriamente e/ou perifericamente. Isso ocorre pela diversidade de condições de identificação quanto a este modelo, devido: (a) a como o sujeito encarna seus desejos, muitas vezes não fazendo parte de uma condição totalmente orientada para o mesmo sexo, mas em experimentos esporádicos e em desejos e sensações que se produzem de forma difusa quanto ao objeto de prática sexual; (b) a como os sujeitos mobilizam representações sociais quanto ao homoerotismo, tornando também difusas representações contidas em aspectos de desvio social, de definição de cultura alternativa gay, de masculino e de feminino (em seus práticas e valores estéticos); (3) a como diferentes sujeitos se inserem em aprendizados sobre o "ser gay" em determinados lugares de encontros gays, isso determinado pela diferente capacidade de se pagar para inserir-se em um mercado cultural que define a reprodução de certas práticas e estética em determinados sujeitos; (4) a como são as formas de encontros e convivências gays em determinadas regiões e cidades, ou seja, em que circunstância o mercado gay local se desenvolve tornando possível a reprodução de certas práticas gays universalizantes e/ou tornando unificadas ou diversas as identificações de grupos gays diferenciados na cidade (se a quantidade de lugares gays reproduz uma 
diversidade ou uma restrição de propostas estéticas, de classe e de práticas homoeróticas vinculadas a tais lugares).

\section{AS MICROTERRITORIALIDADES HOMOERÓTICAS E/OU HOMOAFETIVAS EM DIFERENTES CONTEXTOS URBANOS BRASILEIROS}

O que observamos em grandes cidades, como em Porto Alegre e São Paulo, por exemplo, é a diversificação de lugares que se definem pela frequência de determinadas expressões dos sujeitos orientados sexualmente para o mesmo sexo, ou seja, o desenvolvimento do mercado gay tornou diversificados os lugares de frequência gay e produz uma diversificação das identidades de gays que os frequentam. Podemos dizer que tais territórios são definidos pela cultura de seus frequentadores que se diferenciam por: (a) capacidade de pagar para frequentar o lugar; (b) origem (urbana) de seus frequentadores; (c) tipo de música que gostam de ouvir; (d) faixas etárias; (e) práticas que se estabelecem (sexo direto, festa, relações "bicha-bofe", "michê-contratante", happy hour, lugar de encontro de amigos, lugar de frequência solitária etc); (f) tipo de festa que se organiza (rave, funk, música instrumental, show de drag, nostalgia etc).

No contexto de São Paulo, o padrão hegemônico é condicionado ao desejo de frequentar o lugar e às práticas e estéticas contidas nele. Tal padrão hegemônico define-se pela condição estética de determinados lugares, cuja possibilidade de frequência implica capacidade de se pagar para conviver: como, por exemplo, uma a boate específica, que também mantêm filiais no Rio de Janeiro e Florianópolis. Em relação a este padrão hegemônico cultural gay, outras condições de identificação da reunião se diversificam em planos horizontais definindo "os de fora" e os "ao lado" (FORTUNA, 2002). Àqueles que estão periféricos a determinados modelos de cultura hegemônicas condicionadas ao mercado, resta criatividade quanto à produção de suas práticas e estéticas. Tal criatividade não se apresenta totalmente distanciada dos modelos hegemônicos, são reproduzidas por outras óticas e outras condições. Outras formas não hegemônicas também estão condicionadas a um mercado de diversão que se diversifica. Assim, os encontros homoeróticos na cidade de São Paulo se diversificam pela variabilidade de um mercado quanto ao valor que mobiliza, quanto aos atributos estéticos que geram diferenciadas performances de corpos, quanto à identificação de seus frequentadores.

O circuito (PARKER, 2002) gay paulistano é definido por um conjunto de lugares e trajetos cujas localizações mobilizam processos de identificação daqueles presentes e que experimentam as relações estabelecidas "aqui" e "agora" (MAFFESOLI, 2002). Produzem-se múltiplas identificações condicionadas à variabilidade da aceitação e da negação individual de certas práticas e de valores estéticos de seus frequentadores. Isso está condicionado às representações contidas nos discursos dos gays em geral, que, muitas vezes de forma preconceituosa e discriminatória, articulam certos atributos estigmatizantes daqueles "outros" que frequentam determinado lugar. Por outro lado, existem divergências quanto à representação que se estabelece dos lugares e de 
seus frequentadores e as reais práticas e pré-disposições dos sujeitos que realmente o frequentam.

Em primeiro momento, não ocorre exatamente agregados de sujeitos que frequentam exclusivamente determinados lugares, o que ocorre é o experimento de diferentes lugares e a mobilização performática de subjetividades para com a objetividade da situação ali produzida (que aponta para uma tentativa de concordância a determinadas práticas e estéticas, ou somente um experimento sobre o que há de discordante a seus desejos e identificações estéticas). Em segundo momento, as relações entre os sujeitos, suas performances, seus gostos e interesses afetivos são muito mais complexos que uma representação uniforme sobre o que ocorre no lugar (definida como um discurso de produz atributos diferenciados a lugares diferenciados de um circuito gay de São Paulo).

O que observamos é que existe sim a localização das convivências e a formação de um circuito gay paulista, cuja centralidade é a rua Vieira de Carvalho, no centro da cidade; que os lugares se diferenciam quanto às propostas estéticas e quanto ao que se faz; e que certos lugares reproduzem certas representações unitárias de um mundo gay. No entanto, por outro lado, este circuito se define mais pela complexidade das formas espaciais e expressão dos corpos, próximo à ideia de pastiche (BRAGA JUNIOR, 2006), antes discutida, e isso torna muito complexas e difíceis de serem definidas simploriamente a qualidade das relações e dos sujeitos inseridos em cada "canto" e "pedaço" deste circuito.

Mesmo assim, percebemos que o mercado se apega a certas representações para diversificar certas localizações de encontros, mesmo que o fluxo de participantes seja flutuante e a localização somente defina um padrão de certos experimentos e não uma população assídua que realmente pode ser identificada e se identifica com o lugar. Talvez a identificação seja condicionada ao estar naquela condição espaço-temporal em que sujeitos mobilizam subjetivamente certas condições representativas sobre seu "eu" e a situação e objetivam-nas na interação social.

A situação da interação social é influenciada por uma representação hegemônica do lugar de encontro, mas não é exatamente unificadora das performances dos corpos em interação. Os sujeitos circulam em prol do exercício das afetividades e sexualidades, como que se estivessem em deriva (PERLONGHER, 1987; PERLONGHER, 2005) por entre as possibilidades de situações de encontro homoerótico na cidade. Em primeiro momento, se apegam a certas representações sobre os lugares colhidas de suas interações cotidianas, nas quais absorvem discursos e acreditam sobre o que ocorre em determinados lugares é uma verdade. Por outro lado, apresentam-se abertos ao experimento, mesmo que em determinados sujeitos esta capacidade de experimentar seja mais acentuada e, em outros, a acomodação à representação seja mais evidente. Geralmente ocorre uma necessidade de experimentar as diversas possibilidades de convivências do circuito e a tendência posterior à acomodação pela maior identificação com certos aspectos contínuos que caracterizam a convivência de um determinado lugar. Elementos como identidade estética, faixa etária, capacidade de pagar para entrar em certos lugares da moda, busca sexual e certa representação para com o desejo e as sensações homoeróticas vão determinar a agregação de certos sujeitos e suas frequências mais assíduas em 
certos lugares. Mas entre a quantidade e qualidade das necessidades afetivas e sexuais e as expressões estéticas de sujeitos que somente experimentam e sujeitos que se apegam a certas representações que possam condicionar o lugar, a realidade da característica cultural da microterritorialização de interação homoerótica apresenta-se muito complexa em se definir.

Em Porto Alegre, não se observa uma diversidade de representações sobre determinados lugares de frequência gay e/ou GLS, assim como não se observa a formação de um circuito que concentra equipamentos comerciais e pontos de interação (" pegação") em lugares públicos. Boates com capacidade de entreter um grande número de pessoas são muito mais definidas pela diversidade de expressões dos sujeitos em interação. Não existem, por exemplo, boates especializadas em frequência de "ursos", ou senhores de faixa etária mais elevada (embora em algumas saunas ocorra esta frequência mais acentuada), nem de culto à cultura funk de periferia e/ou vinculada à modernidade das raves e/ou vinculadas a certas vanguardas de decoração e de moda plástica, como ocorre em São Paulo. O que pode ocorrer é certas festas que acentuam características específicas, mas que acabam vinculando-se à diversidade de expressões de grupos de sujeitos que a frequentam.

Em cidades do interior do Estado do Rio Grande do Sul, as pesquisas de Costa (2010/2011) apontam pela quase inexistência de um comércio e/ou equipamentos destinados à diversão e encontro de sujeitos orientados para o mesmo sexo. As interações ocorrem camufladas como táticas que produzem rizomas em trajetos e pontos de interação no espaço público, principalmente à noite, como em praças, banheiros públicos e ruas mais desertas. As interações homoeróticas apresentam-se veladas em certos bares e boates não definidos como gays, assim como os encontros sexuais são muito mais possibilitados pela paquera em sites de relacionamento da internet. Algumas festas GLS se produzem pela ação de certos empreendedores que alugam certos lugares e se encarregam da decoração, da música e da venda de bebidas. Estas festas são conhecidas por um público orientado para o mesmo sexo na região próxima à cidade em que ocorrem. No dia da festa, sujeitos de diferentes cidades se reúnem em grupos e se deslocam pelo aluguel de veículos (vans), tornando numerosa a população que frequenta a festa. Alguns concursos como o de miss e mister gay, assim como rainha drag (como em Rosário do Sul) ocorrem pelo interior do Estado, assim como muitas festas relacionadas à promoção de paradas gays por ONGs (Santa Maria e Cruz Alta, por exemplo) que trabalham com a diversidade sexual e cultural, assim como com a prevenção da AIDS/HIV. Poucas cidades apresentam estabelecimentos comerciais noturnos que se especializam em festas gays, algumas cidades são Uruguaiana, Santa Maria, Caxias do Sul, Pelotas e Santa Cruz do Sul (cujas festas da boate up, que antes eram esporádicas, são conhecidas em todo Estado). É comum, porém, a frequência de gays em festas durante o carnaval. Em Alegrete, por exemplo, o concurso de rainha gay faz parte do carnaval, assim como as apresentações de samba de drag queens e travestis fazem parte dos ensaios dos blocos carnavalescos. 


\section{CONSIDERAÇÕES FINAIS}

Em relação a estas observações sobre São Paulo, Porto Alegre e cidades pequenas do interior do Estado do Rio Grande do Sul, podemos concluir que da cidade menor para a cidade grande ocorrem:

1) a maior densidade populacional e o maior desenvolvimento de um mercado cultural de diversão na grande cidade aumenta a quantidade de estabelecimentos cuja relação com uma representação das práticas e identidades dos sujeitos se singularizam;

2) que na grande cidade os diversos estabelecimentos tidos como gays ou que não são exatamente identificados como gays, mas em que ocorrem encontros e afetividades orientadas sexualmente para o mesmo sexo, aliam-se a certas representações sobre a identidade e as práticas de quem os frequentam. Isso diversifica as experiências, as formas de expressão, as práticas e as interações sociais relacionadas às homoafetividades e/ou ao homoerotismo;

3) que os sujeitos se concentram e derivam por um conjunto de trajetos que ligam lugares e encontros homoeróticos e/ou homoafetivos e experimentam as diversas práticas, expressões, formas de interações que ocorrem em diferentes lugares. Os lugares identificam as práticas e os sujeitos que os frequentam, mas a frequência se estabelece pela necessidade de experimentar, na atividade de "deriva" dos sujeitos, pelo circuito de deslocamento. Uma qualidade estética e a possibilidade de praticar certas ações são realizadas pela existência de um mercado de serviços (bares, boates, saunas, cinemas, casas de encontros e de sexo, vídeo locadoras, lan houses, restaurantes etc) que estimulam os sujeitos a experimentar;

4) que tais sujeitos revelam ou camuflam certos desejos, vontades e/ou identificações com certas práticas e expressões estéticas a cada lugar que transitam no circuito de deslocamento homoerótico. Os lugares não são frequentados por uma população fixa, embora muitos sujeitos acabem preferindo frequentar um lugar a outro, dessa forma não identifica rigidamente seus frequentadores, na complexidade interna de suas relações, mas mais abarcam algumas representações estimuladas por aqueles que falam de fora dele, mas que, mesmo discriminando ou denotando resignação a alguma prática ou forma estética, já tenha experimentado em algum momento a convivência nele;

5) este trânsito por diversos lugares e as relações diferenciadas aqui e acolá produzem um complexo aprendizado sobre a qualidade das sensações estéticas vinculadas ao homoerotismo. Os sujeitos agregam certas expressões paradoxais em relação a certos atributos tidos como rígidos a certos objetos, como a definição de masculino, de feminino, de funkeiro, de roqueiro, de machão, de bicha etc. As composições culturais mistas (híbridas) produzem novas culturas de agregados de sujeitos orientados para o mesmo sexo, possibilitadas pela reunião em um determinado "pedaço" ou "canto" (um bar, uma boate, uma esquina, uma galeria etc) do circuito homoerótico já estabelecido. 
Assim se diversificam as identificações, as experimentações, mas também os estranhamentos, discriminações e preconceitos de certos sujeitos em relações a outros, mesmo todos se revelando praticantes de sexo com pessoas do mesmo sexo.

6) que nesta produção cultural híbrida de microgrupos relacionais em microterritorializações de encontros e de produção de certas práticas e compartilhamentos estéticos e discursivos, a qualidade de gay não pode mais ser descrita de forma simplória, a não ser que designe somente a relação sexual para com o mesmo sexo. O que se concebe como gay na cidade grande é muito diverso e misturado e isso aponta a ideia de Braga Junior (2006) sobre a concepção da cultura gay como um pastiche;

7) que no entanto, mesmo apresentando uma maior diversidade de expressões estéticas e comportamentos, certas representações sobre certos lugares de frequência gay tornam-se mais rigidamente determinantes de certos tipos de práticas, afetividades e expressões estéticas dos sujeitos frequentadores. Isso conduz a uma maior discriminação explicitada em discursos entre diferentes sujeitos orientados para o mesmo sexo, que convivem no circuito gay paulista, por exemplo, tornando este circuito construído por "espaços de proximidade" (FORTUNA, 2002), cujos sujeitos se toleram, mas não se misturam ou negam certas representações sobre si e sobre os outros a convivência. Ao mesmo tempo em que discursivamente nega-se a convivências em determinados lugares cujas qualidades dos sujeitos de frequências é rejeitada, experiências esporádicas de frequência se produzem como um experimento camuflado e solitário que não se revela entre grupos de amigos diretos;

8) os jogos de identificações em um circuito homoerótico são maiores na grande cidade e produzem "topofobias" e "topofilias" (TUAN, 1980) em espaços de proximidade deste circuito. $\mathrm{O}$ gosto ou a rejeição de frequência em determinados lugares se dialetiza com a propensão ao experimento de convivência por proximidade espacial. Identificar-se ou não como frequentador de um determinado lugar apresenta-se mais como discursos que como prática (que aponta a deriva por entre diferentes lugares). A representação coletiva sobre o que determina as características de convivência de determinados lugares no circuito homoerótico paulista, por exemplo, se evidencia mais como representação simplória do que a complexidade de situações de interação que podem ocorrer efetivamente em determinado lugar;

9) o mercado acaba reforçando certas identificações mais rígidas quanto à frequência de determinados sujeitos orientados sexualmente para o mesmo sexo, o que acaba domesticando (FORTUNA, 2002) certas práticas e certas representações em determinados lugares. A domesticação das práticas culturais aponta para a diversificação acentuada da representação da identidade que separa sujeitos e produz processos de discriminação em espaços de proximidade de um circuito gay que se pensa como homogêneo, mas não o é; 
10) na cidade grande, os posicionamentos (quanto ao segmento social, quanto à qualidade de gosto e expressão estética, quanto às suas posturas e práticas quanto ao homoerotismo) dos sujeitos se diversificam tornando mais acentuados os estranhamentos, os preconceitos e as discriminações por entre uma população orientada para o mesmo sexo que fragmenta suas expressões e representações estimuladas pelo mercado flexível;

11) ocorre, assim, uma maior convergência quanto ao desejo homoerótico (definindo um circuito concentrado), mas uma maior divergência quanto ao status social e a forma de compartilhamento cultural de determinados agregados de sujeitos;

Assim, perguntamos como avaliar o multiculturalismo da grande cidade? O que observamos na cidade grande é que a diversificação estética do mercado distribuído em um circuito em espaços de proximidade produz uma maior diversificação das práticas relacionais quanto ao homoerotismo que rompe o caráter transgressor sobre o espaço público, não questiona a sociedade heteronormativa e multiplica representações separando microgrupos relacionais;

Enquanto na menor cidade o mercado gay é menos desenvolvido e as possibilidades de convivência entre sujeitos orientados para o mesmo sexo são mais restritas, a pouca "guetificação" introduz uma maior convivência destes sujeitos com o restante da sociedade, o que se observa, por exemplo, na inserção de famílias e demais sujeitos em eventos gays das cidades do interior do Rio Grande do Sul e a livre expressão gay e homoerótica no carnaval destas cidades. Na cidade maior, os bares e boates gays guetificam os gays, assim como a diversidade destes estabelecimentos torna rígidas diferentes representações sobre diferentes gays, o que separa e determina preconceitos e discriminações entre a própria população orientada para o mesmo sexo.

\section{REFERÊNCIAS}

BRAGA JUNIOR, Luiz Fernando Lima. Caio Fernando Abreu: narrativa e homoerotismo. 2006. Tese (Doutorado em Literatura). Faculdade de Letras, Universidade Federal de Minas Gerais, Belo Horizonte.

COSTA, Benhur Pinós da. A condição homossexual e a emergência de territorializações. Dissertação (Mestrado em Geografia) - Programa de Pós-Graduação em Geografia, UFRGS, Porto Alegre, 2002.

;HEIDRICH, Alvaro Luiz. A condição dialética de produção do espaço social: microterritorializações (culturais) urbanas "a favor" e "contra" a sociedade. In: KOSEL, Salete; SILVA, Josué da Costa; GIL FILHO, Sylvio Fausto. Da percepção e cognição a representação: reconstruções teóricas da Geografia Cultural e Humanista. São Paulo: Terceira Imagem; Curitiba: NEER, 2007. p. 80-113.

Por uma Geografia do cotidiano: território, cultura e homoerotismo na cidade. 2008. Tese (Doutorado em Geografia) - Programa de Pós-graduação em Geografia, UFRGS, Porto Alegre.

Cidades, espaço público e diversidades culturais no interior do Estado do Rio Grande do Sul: o caso das microterritorialidades de expressões homoeróticas e/ou homoafetivas em contextos urbanos próximos a Santa Maria-RS. Projeto de pesquisa Edital Auxílio ao Recém Doutor (ARD) - Fundação de Amparo o Pesquisa do Rio Grande do Sul (FAPERGS). FAPERGS, UFSM: Santa Maria-RS, 2010-2011.

DE CERTEAU, Michel. A invenção do cotidiano: artes de fazer. Petrópolis: Vozes, 1994. V. 1. 
DELEUZE, Gilles. Conversações 1972-1990. São Paulo: Editora 34, 1996.

DUNCAN, James. O supra-orgânico na Geografia Cultural Americana. In: CORRÊA, R. L.; ROSENDAHL, Z. Introdução à Geografia cultural. Rio de Janeiro, Bertrand Brasil, 2003. p 7-33.

FORTUNA, Carlos. Culturas urbanas e espaços públicos: sobre as cidades e a emergência de um novo paradigma sociológico. Revista Crítica de Ciências Sociais, v.63. outubro, 2002.

FOUCAULT, Michel. Microfísica do poder. Rio de Janeiro: Graal, 1993.

GIDDENS, Anthony. Identidade e modernidade. Rio de Janeiro: Jorge Zahar, 2002.

GOFFMAN, Erving. A representação do eu na vida cotidiana. Petrópolis: Vozes, 1996.

HELLER, Agnes. Sociologia de la vida cotidiana. Barcelona: Península, 1991.

HOLLAND, Ray. Eu no contexto social. Rio de Janeiro: Zahar, 1979.

HONNETH, Axel. Luta pelo reconhecimento: a gramática moral dos conflitos sociais. São Paulo: Editora 34, 2003.

JAMESON, Frederic. O pós-modernismo: e a lógica cultural do capitalismo avançado. São Paulo: Ática, 1991.

LOURO, Guacira Lopes. Teoria Queer: uma política pós-identitária para a educação. Revista Estudos

Feministas. Florianópolis: CFCH/CCE-UFSC. V. 9, n. 2, 2001. Disponível em: <http://www.scielo.br/ pdf/ref/v9n2/8639.pdf>. p. 541-553. Acesso em: 22 maio 2011.

MACLAREN, Peter. Multiculturalismo crítico. São Paulo: Bebel Orofino Schaefer, 2000.

MAFFESOLI, Michel. O tempo das tribos: o declínio do individualismo nas sociedades de massa. Rio de Janeiro: Forense Universitária, 2002.

PARKER, Richard. Abaixo do Equador: culturas do desejo, homossexualidade masculina e comunidade gay no Brasil. São Paulo: Record, 2002.

PERLONGHER, Nestor. O negócio do michê: a prostituição viril. São Paulo: Brasiliense, 1987.

Territórios marginais. In: GREEN, J.; TRINDADE, R. (Org.). Homossexualismo em São Paulo: outros escritos. São Paulo: Ed. UNESP, 2005. p. 263-290.

SANTOS, Boaventura de Souza. Os processos da globalização. In: SANTOS, B. de S. (Org.). A globalização e as ciências sociais. São Paulo: Cortez, 2002. p. 25-104.

SEMPRINI, Andréa. Multiculturalismo. Florianópolis: EDUSC, 1999.

SILVA, Joseli Maria (Org.). Geografias subversivas: discursos sobre espaço, gênero e sexualidades. Ponta Grossa: Todapalavra, 2009.

TOURAINE, Alan; KHOSROKHAVAR, Farhad. Em busca de si: diálogos sobre o sujeito. Rio de Janeiro: Bertrand Brasil, 2004.

TUAN, Y-Fu. Topofilia: Um estudo da percepção, atitudes e valores do meio. Rio de Janeiro: Bertrand Brasil, 1980.

VELHO, Gilberto. Subjetividade e sociedade: uma experiência de geração. Rio de Janeiro: Jorge Zahar, 1989.

Recebido em 14/01/2012

Aceito para publicação em 22/03/2012 